\title{
Overview on solid-state dosimeter-type gas sensors
}

\author{
A. Groß, I. Marr, R. Moos \\ Universität Bayreuth, Lehrstuhl für Funktionsmaterialien, 95440 Bayreuth, Germany \\ Functional.Materials@Uni-Bayreuth.de
}

\begin{abstract}
:
Based on irreversible analyte accumulation in the sensitive layer, dosimeter-type gas sensors are promising for the long-term monitoring of low levels of analytes. Thereby, the analyte dose can be detected either during progressive analyte sorption or release with a direct correlation between the sensor response and the cumulated analyte amount. A short overview on various solid-state resistive dosimeter-type sensors for several gaseous analytes is given in order to demonstrate the potential of this cumulative sensing principle. The focus is on a $\mathrm{NO}_{x}$ sensor based on chemical $\mathrm{NO}_{x}$ storage with linear characteristics concerning the $\mathrm{NO}_{x}$ dose allowing for additional information on the actual $\mathrm{NO}_{\mathrm{x}}$ concentration from the signal derivative.
\end{abstract}

\section{Key words:}

Low level detection, long-term monitoring, accumulation mode, exposure monitoring, real-time gas dosimeter, chemiresistor.

\section{Introduction}

In the field of exhaust or air quality monitoring, the focus is rather on mean values or amounts of analyte exposure (= dose) than on the timely course of the concentration. The mathematical integration of concentration-related sensor responses to determine the dose over longer periods is error-prone. Especially for low analyte levels, the analysis often suffers from noise, zero-level drifts as well as from slow response and recovery times.

On the contrary, real-time dosimeters are particularly suitable for the long-term monitoring of low level exposures without mathematical operations since the sensor response correlates directly with the analyte dose. Average concentrations of highly diluted gases (e.g. the hourly mean value [1-3]) can be determined easily from the sensor response accounting for the duration of exposure. Due to their irreversible analyte sorption capability, dosimeters are also denoted as (ac-) cumulating $[2-5]$ or integrating $[3,6,7]$ devices.

Analyte accumulation in the sensitive layer can be realized by chemical reactions $[2,6,8,9]$, or by apparently irreversible sorption processes $[7,10,11]$. Therefore, the proper choice of the sensitive material is essential to obtain a dosimeter-type sensing behavior under the applied conditions $[3,10]$.

\begin{abstract}
After an introduction to the dosimeter-type sensing principle, a short overview on resistive gas dosimeters for various analytes is given. The diverse functionalities of a $\mathrm{NO}_{x}$ dosimeter based on chemical $\mathrm{NO}_{x}$ storage are described in detail.
\end{abstract}

\section{Background on the dosimeter-type sensing principle}

Similar to passive samplers, dosimeter-like gas sensors are operated in two alternating steps as shown in Fig. 1. During the sorption period, analyte molecules are progressively accumulated in the adsorbent layer followed by a short-term regeneration to release the formerly sampled molecules.

An analyte loading level dependent physical property of the adsorbent serves as sensor signal $R$. In resistive dosimeters the resistance $R$ might serve as measurand. $R$ increases with proceeding exposure and recovers as the initial state of the adsorbent is restored. Therefore, analyte detection might be performed either during sorption [6,7,12] or release [13]. Mainly optical [2,5,9], gravimetric [8], and recently impedimetric $[1,6,12,14-17]$ dosimeters are reported. 


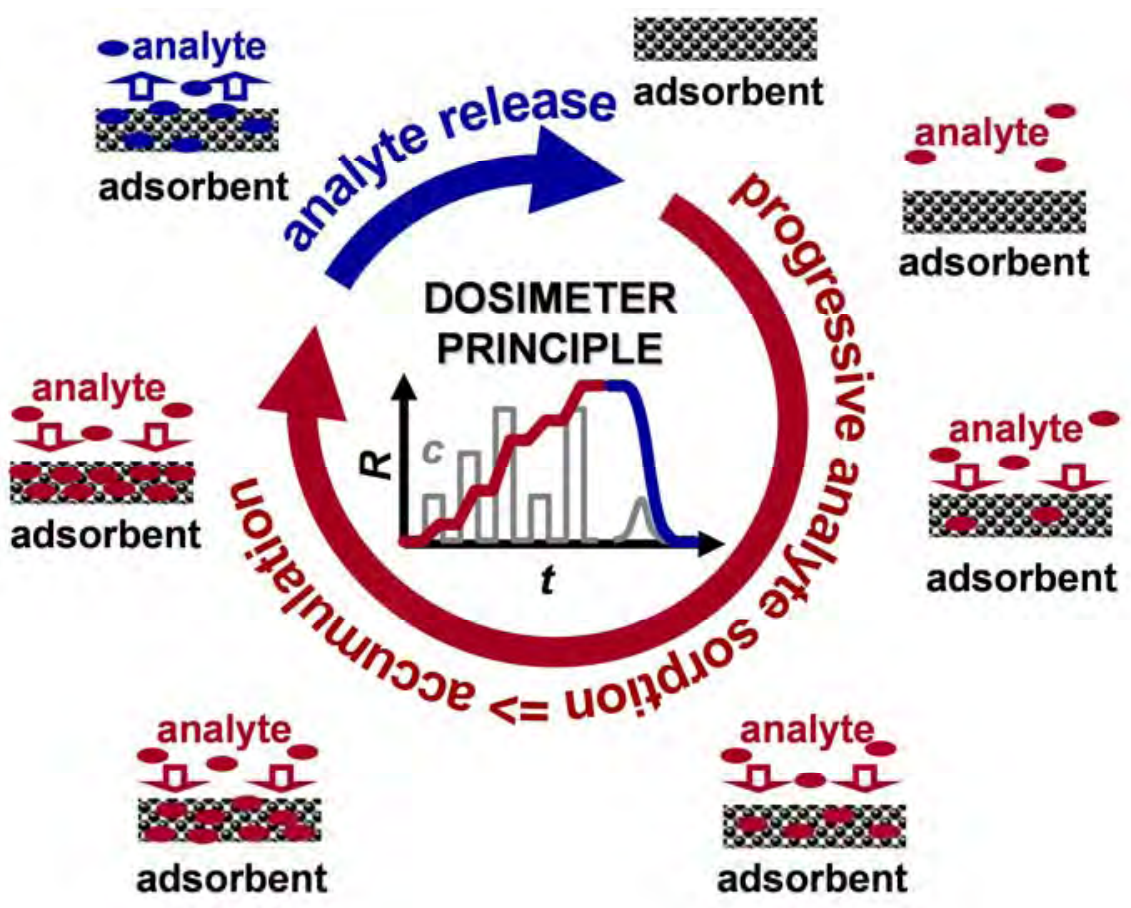

Fig. 1. Principle of dosimeter operation: alternating analyte sorption and regeneration periods with an exposure dependent sensor response $R$.

The direct amount sensing characteristics of a resistive dosimeter during analyte sorption are sketched in Fig. 2 for a constant gas flow rate [18]. Then, the dose or cumulated amount $A$ is proportional to the timely integral of the exposed concentration $c$ in the unit $\mathrm{ppm} \cdot \mathrm{s}[3,5,12]$. Consequently, the measurand $R$ (e.g. the resistance) increases irreversibly in the presence of analyte $[7,8,15,16]$. Ideally, the analyte sorption rate of the adsorbent is proportional to $c$ resulting in a linear characteristic line between $R$ and the dose $A[3,18]$. Due to this proportionality, the course of the analyte concentration can be obtained from the signal derivative $\mathrm{d} R / \mathrm{d} t[2,3,7,10]$. The amount-sensitivity $S_{\mathrm{A}}$ is given as $\mathrm{d} R / \mathrm{d} A[3-5,9]$, e.g. in $\% / p p m \cdot h$ or $\% / \mu l$, and is proportional to the common concentration-sensitivity $S_{c}$ [4].

Once the sorption sites of the adsorbent are saturating, the analyte accumulation rate decreases. Regeneration needs to be initiated to recover the performance of the dosimeter $[3,4,6,7,10]$. Depending on the interaction between the adsorbent and the analyte, analyte release might occur e.g. thermally $[3,11,17,19]$, chemically by other gas components $[6,15,17,19]$, or upon exposure to UV light $[16,17]$. Otherwise the dosimeter is a disposable device allowing only for a one-shot detection $[8,10]$. Advantageously, the zero level of the dosimeter-type sensor response is selfredefined by regeneration, avoiding long-term signal drifts [3].

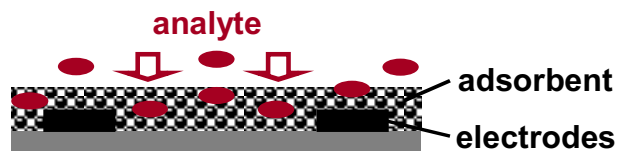

1.) Direct dose detection
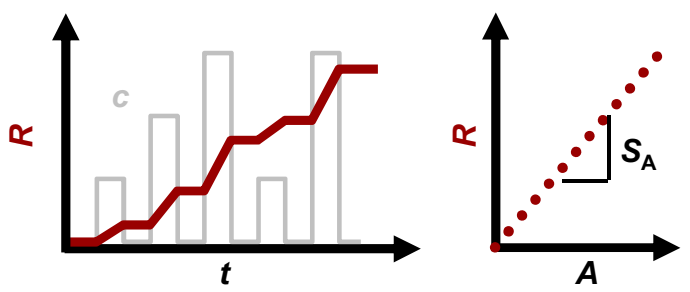

2.) Concentration detection via derivative
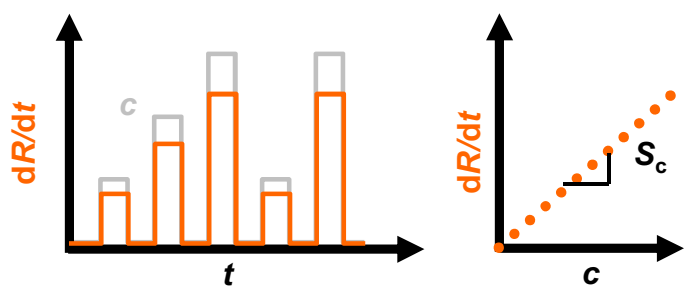

Fig. 2. Evaluation of sensor response $R$ in the sorption mode to determine: (1) directly the analyte dose and (2) indirectly the timely analyte concentration. 


\section{The resistive accumulating $\mathrm{NO}_{\mathrm{x}}$ sensor}

As a first example for solid-state gas dosimeters, a $\mathrm{NO}_{x}$ accumulating device is described.

The $\mathrm{NO}_{\mathrm{x}}$ sorption capability of the presented $\mathrm{NO}_{\mathrm{x}}$ dosimeter is based on a lean $\mathrm{NO}_{\mathrm{x}}$ trap known from automotive catalysts. In the temperature range of 350 to $450{ }^{\circ} \mathrm{C}, \mathrm{NO}$ and $\mathrm{NO}_{2}$ are oxidized and stored chemically by a carbonate to nitrate conversion under excess oxygen [6]. The resistivity of the adsorbent decreases with progressive nitrate formation [6,14]. This enables dosimeter-type total $\mathrm{NO}_{\mathrm{x}}$ detection under $\mathrm{NO}_{\mathrm{x}}$ oxidizing and sorption conditions $[3,4,11,20]$ with a comparable sensitivity to $\mathrm{NO}$ and $\mathrm{NO}_{2}[3,4]$. $\mathrm{NO}_{x}$ release via nitrate decomposition is achieved upon heating to $650{ }^{\circ} \mathrm{C}[20]$ or in reducing atmospheres $[3,6]$ enabling a periodic recovery of the storage sites and of the sensitivity.
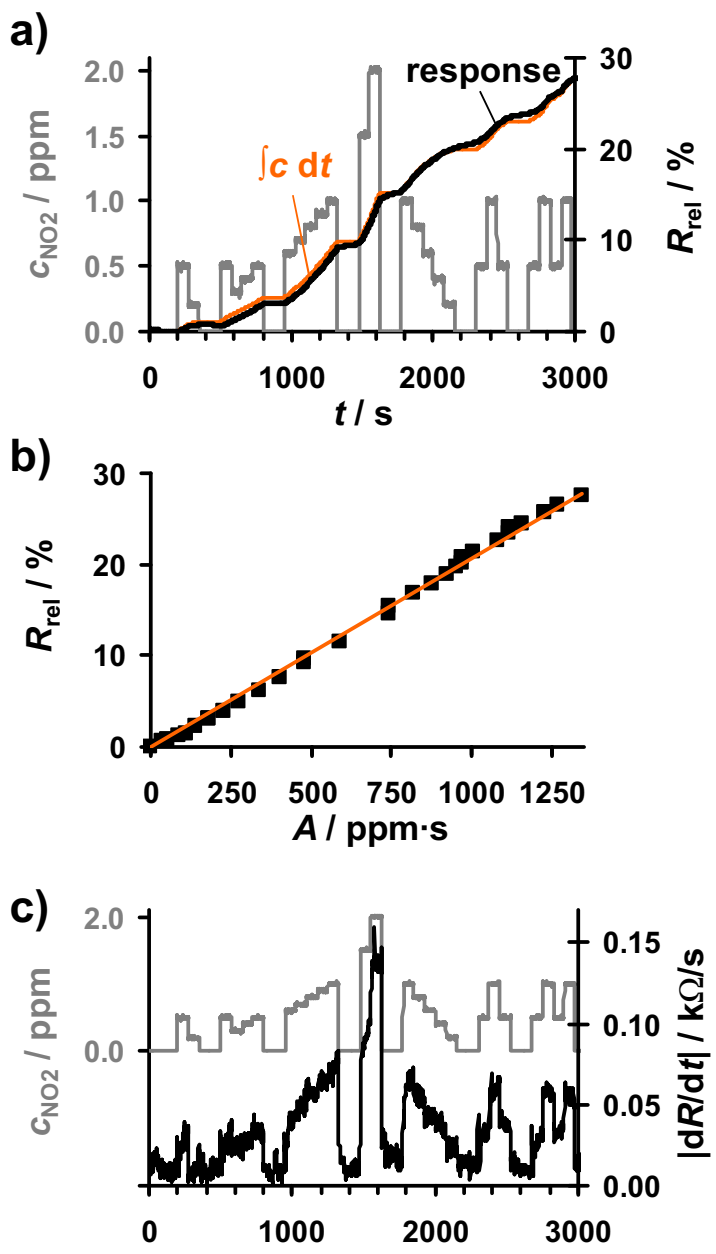

Fig. 3. Low level $\mathrm{NO}_{2}$ detection (0.2 to $2 \mathrm{ppm}$ for $75 \mathrm{~s})$ : a) response $R_{\text {rel }}$ proportional to $\int \mathrm{C}_{\mathrm{NO} 2} \mathrm{~d}$ t, b) amount related characteristic line, c) derivative $|\mathrm{d} R / \mathrm{d} t|$ proportional to $c_{\mathrm{NO} 2}$. Adapted from [3].
The suitability of the $\mathrm{NO}_{x}$ dosimeter for the long-term $\mathrm{NO}_{2}$ detection with concentrations in the sub-ppm range is shown in Fig. 3 [3]. The absolute value of the relative resistance change $R_{\text {rel }}$ is monitored as sensor response during intervals with 0.2 to $2 \mathrm{ppm} \mathrm{NO}$ as indicated in Fig3a. $R_{\text {rel }}$ increases stepwise in the presence of $\mathrm{NO}_{2}$. More precisely, $R_{\text {rel }}$ follows the course of the timely integral of the concentration $c$ that is representing the cumulated $\mathrm{NO}_{2}$ amount $A$. The resulting characteristic line in Fig. $3 b$ clarifies the linear correlation between $R_{\text {rel }}$ and $A$ up to about $30 \%$ with a sensitivity of $0.021 \% / \mathrm{ppm} \cdot \mathrm{s}$. The time derivative of the resistance $|\mathrm{d} R / \mathrm{d} t|$ in Fig. $3 \mathrm{c}$ is almost proportional to course of the concentration $c(t)$.

Fig. 3 reveals that in contrast to common gas sensors, the presented $\mathrm{NO}_{x}$ dosimeter detects directly and time-continuously the cumulated amount of $\mathrm{NO}_{2}$ in the sorption mode, while the actual concentration can be estimated from the slope (timely derivative). Concerning $\mathrm{NO}_{2}$, the EU immission legislation permits a 1 -hour value of $200 \mu \mathrm{g} / \mathrm{m}^{3}$ and an annual mean value of $40 \mu \mathrm{g} / \mathrm{m}^{3}$ [21]. According to the linear measurement range reported in Fig. 3 , the 1hour value could be monitored linearly by the $\mathrm{NO}_{x}$ dosimeter for about $3.7 \mathrm{~h}$ without regeneration and the annual value for even $18.5 \mathrm{~h}$.

In accordance to the catalytic properties, it was demonstrated that the sensitivity of the $\mathrm{NO}_{x}$ dosimeter increases with temperature while the linear measurement range decreases [3,22]. At $650{ }^{\circ} \mathrm{C}$, the resistance changes reversibly in $\mathrm{NO}_{x}$ indicating missing $\mathrm{NO}_{x}$ accumulation properties and thermodynamic instability of nitrates [20]. The presence of oxygen is essential, but variations of $\mathrm{O}_{2}$ and $\mathrm{CO}_{2}$ in a wide concentrations range have no significant effect on the dosimeter-like $\mathrm{NO}_{x}$ sensing characteristics [6]. The missing oxidizing properties of pure carbonates enable $\mathrm{NO}_{2}$ dosimetry without $\mathrm{NO}$ sensitivity $[14,23] . \mathrm{SO}_{2}$ deteriorates the $\mathrm{NO}_{\mathrm{x}}$ sorption capacity and affects the resistivity requiring regeneration at elevated temperatures and in reducing atmospheres [24]. Hence, $\mathrm{SO}_{2}$ dosimetry can be achieved with the same setup [24].

It was shown that the arrangement of the adsorbent in the gas flow influences the $\mathrm{NO}_{\mathrm{x}}$ sorption $[18,20]$. One can distinguish between an amount detector due to complete $\mathrm{NO}_{x}$ uptake or a flow rate independent concentration integrator [18]. A rotational symmetry of the transducer geometry was found to be particularly advantageous for analyte sorption in dosimeters [20]. The self-heated tubular ceramic platforms allowed for a sensitivity 
adaption by an easy adjustment of the temperature of the adsorbent and periodic thermal regeneration. Differently heated zones in the tubular setup equipped with various adsorbent layers are intended to enlarge the functionality.

Additionally, the $\mathrm{NO}_{\mathrm{x}}$ dosimeter characteristics can be adapted by the adsorbent thickness as explained in detail in [4]. The test series included adsorbent layers of 30,60 and $90 \mu \mathrm{m}$ deposited on electrodes with $100 \mu \mathrm{m}$ spaces. All samples show $\mathrm{NO}$ and $\mathrm{NO}_{2}$ cumulative sensing behavior and a linear sensing characteristics independent on the $\mathrm{NO}_{x}$ species. However, the sensitivity increases with the inverse thickness. Independent on the thickness, the linear measurement range is limited by $30 \%$ sensor response and consequently decreases with increasing sensitivity.

\section{Overview on other resistive gas dosimeters}

As already mentioned, the dosimeter's response correlates with analyte loading state of the adsorbent. The loading state is dependent on the analyte exposure, in particularly the concentration and the duration. In the following further examples of solid-state dosimeters based on resistive measurement principles are given. The adsorbent materials range from polymers to ceramics and metals and analyte detection is achieved either during analyte sorption or release at various temperatures.

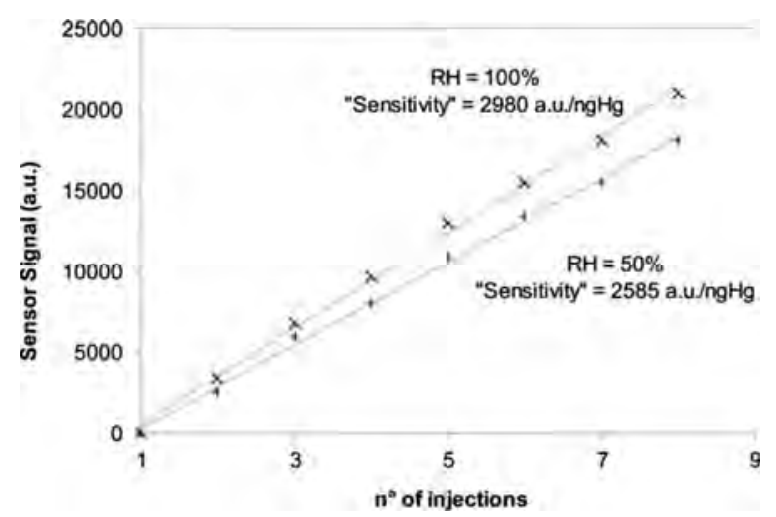

Fig. 4. Resistive dosimeter to monitor the personal exposure to gaseous mercury by a thin gold film. Reprinted from Ref. [1], Copyright (2007), with permission from Elsevier.

Mattoli et al. [1] developed a low-cost, wearable dosimeter based on thin gold films. This dosimeter is proposed for the long-term and real-time monitoring of the personal exposure to gaseous mercury in indoor applications. Upon diffusion controlled sampling of $\mathrm{Hg}^{0}$ in the sampling chamber, amalgam is formed on the gold film and the resistance increases. Fig. 4 reveals the dosimeter-like sensing characteristics by a dependency of the sensor response on the number of consecutive injections of $12 \mathrm{ng} \mathrm{Hg}{ }^{0}$.

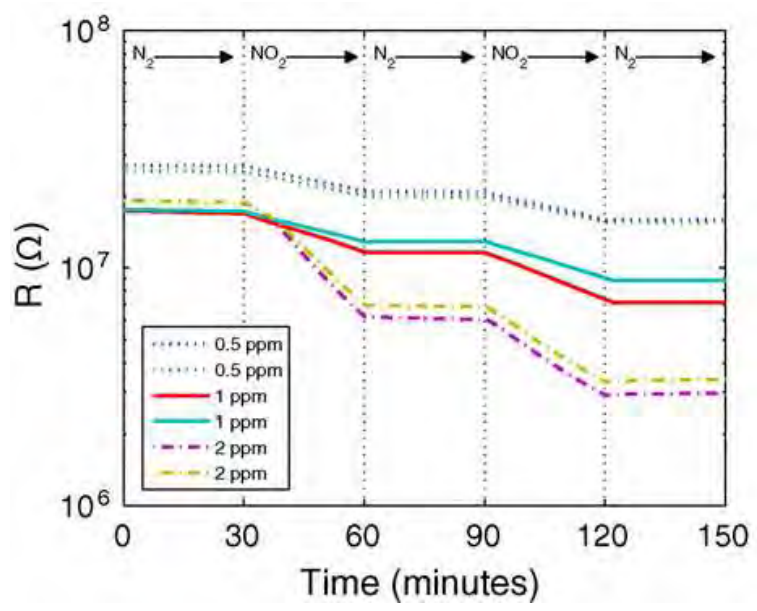

Fig. 5. Low level $\mathrm{NO}_{2}$ dosimeter based on iron (II) phthalocyanine operated at room temperature. Reprinted from Ref. [7], Copyright (2010), with permission from Elsevier.

Iron phthalocyanine (FePc) is applied as $\mathrm{NO}_{2}$ sensitive chemiresistor by Shu et al. [7]. Forming a charge carrier complex, $\mathrm{NO}_{2}$ as electron acceptor results in an increase in the conductivity. As shown in Fig. 5, FePc allows for resistive-type low level $\mathrm{NO}_{2}$ dosimetry at room temperature since the $\mathrm{NO}_{2}$ adsorption is irreversible in the non-saturated state. Higher temperatures accelerate the adsorptiondesorption kinetics, the adsorbent can be regenerated, and the resistance correlates with the $\mathrm{NO}_{2}$ concentration. Like for the $\mathrm{NO}_{\mathrm{x}}$ dosimeter in Fig. 3c, the derivative of the dosimeter-type sensor response is evaluated to obtain concentration information.

Recently, Hennemann et al. [12] reported on the $\mathrm{H}_{2} \mathrm{~S}$ dose sensing characteristics of $\mathrm{CuO}$ nanofibers. Forming $\mathrm{CuS}$ in $\mathrm{H}_{2} \mathrm{~S}$, the conductivity increases by several orders of magnitude. After reaching the percolation threshold, $\mathrm{H}_{2} \mathrm{~S}$ can be electrically detected stepwise as shown in Fig. 6. While $\mathrm{H}_{2} \mathrm{~S}$ accumulates on $\mathrm{CuO}$ at $160^{\circ} \mathrm{C}$, the nanofibers are regenerated at $3500^{\circ} \mathrm{C}$. 


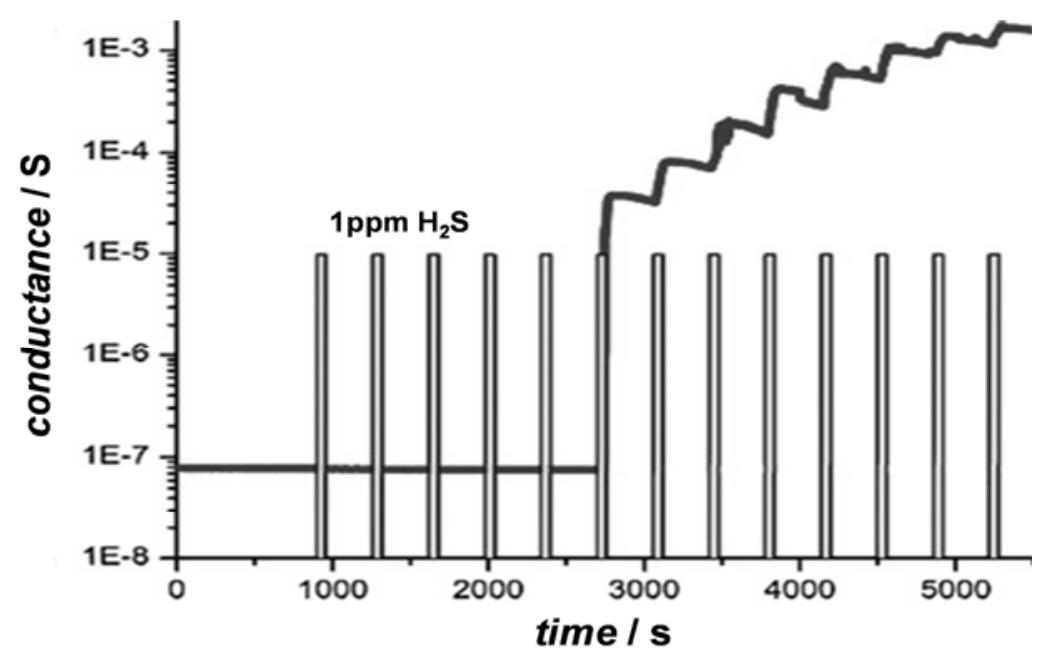

Fig. 6. $\mathrm{H}_{2} \mathrm{~S}$ dosimetry by electrospun copper oxide nanofibers at $160{ }^{\circ} \mathrm{C}$ in $1 \mathrm{ppm} \mathrm{H}_{2} \mathrm{~S}$ pulses being affected by a percolation threshold. Adapted from [12].

Helwig et al. [19] published a review article on the low temperature response of semiconductor gas sensors. Comparing the sensitivity to gaseous species of several semiconducting materials below $150^{\circ} \mathrm{C}$ reveals, that the dosimeter-like sensing properties origin from acid or base reactions. The electrolytic dissociation of the analyte in adsorbed water at the surface results in a $\mathrm{pH}$ change affecting the electrical properties of the semiconductor. The sensor response is recovered in UV light or $\mathrm{O}_{3}$. Additionally, the thin water layers at the surface may serve as single-use sensitive layers by alternately condensing and evaporating water [25].

While the latter dosimeters detect the analyte amount in the sorption mode, Kubinski et al. [13] introduce a $\mathrm{NH}_{3}$ dosimeter operated during the release of the formerly sorbed analyte.

\section{Conclusions}

The operation principle of gas dosimeters is described in detail. Further, examples for resistive-type gas dosimeters are given. Dosimeters are operated either in the analyte sorption or release mode. Both allow for the detection of the analyte dose, but only the former gives real-time and time-continuous information on the analyte exposure evolution.

Solid-state gas dosimeters are beneficial in the field of long-term monitoring of low levels of analytes compared to common gas sensors. The sensor response correlates directly with the cumulated amount. This enables dose detection without the need for a mathematical integration of concentration-related signals. Those are often affected by noise or long-term drifts upon exposure to low levels of analytes. Hence, the analyte accumulating character of dosimeters enhances the accuracy of the determination of mean values or doses. Additionally, the course of the analyte concentration can be estimated from the signal derivative if the dosimeter provides linear sensing characteristics unaffected by varying flow rates.

\section{Acknowledgement}

R.M. thanks the German Research Foundation (DFG) for supporting this work under grant number MO 1060/15-1.

\section{References}

[1] V. Mattoli, B. Mazzolai, V. Raffa, A. Mondini, P. Dario, Design of a new real-time dosimeter to monitor personal exposure to elemental gaseous mercury, Sensors and Actuators B: Chemical 123, 158-167 (2007), doi: 10.1016/j.snb.2006.08.004

[2] T. Tanaka, A. Guilleux, T. Ohyama, Y.Y. Maruo, T. Hayashi, A ppb-level $\mathrm{NO}_{2}$ gas sensor using coloration reactions in porous glass, Sensors and Actuators B: Chemical 65, 247-253 (1999), doi: 10.1016/S0925-4005(99)00185-9

[3] A. Groß, G. Beulertz, I. Marr, D.J. Kubinski, J.H. Visser, R. Moos, Dual Mode $\mathrm{NO}_{x}$ Sensor: Measuring both the accumulated amount and instantaneous level at low concentrations, Sensors 12, 2831-2850 (2012), doi: $10.3390 / \mathrm{s} 120302831$ 
[4] A. Groß, M. Richter, D.J. Kubinski, J.H. Visser, R. Moos, The effect of the thickness of the sensitive layer on the performance of the accumulating $\mathrm{NO}_{x}$ sensor, Sensors 12, 12329-12346 (2012); doi: 10.3390/s120912329

[5] Y.Y. Maruo, Measurement of ambient ozone using newly developed porous glass sensor, Sensors and Actuators B: Chemical 126, 485-491 (2007), doi: 10.1016/j.snb.2007.03.041

[6] A. Geupel, D. Schönauer, U. Röder-Roith, D.J. Kubinski, S. Mulla, T.H. Ballinger, H.-Y. Chen, J.H. Visser, R. Moos, Integrating nitrogen oxide sensor: A novel concept for measuring low concentrations in the exhaust gas, Sensors and Actuators B: Chemical 145, 756-761 (2010), doi: 10.1016/j.snb.2010.01.036

[7] J.H. Shu, H.C. Wikle, B.A. Chin, Passive chemiresistor sensor based on iron (II) phthalocyanine thin films for monitoring of nitrogen dioxide, Sensors and Actuators B: Chemical 148, 498-503 (2010), doi: 10.1016/j.snb.2010.05.017

[8] M. Matsuguchi, Y. Kadowaki, M. Tanaka, A QCM-based $\mathrm{NO}_{2}$ gas detector using morpholinefunctional cross-linked copolymer coatings, Sensors and Actuators B: Chemical 108, 572-575 (2005), doi: 10.1016/j.snb.2004.11.044

[9] D.Y. Sasaki, S. Singh, J.D. Cox, P. I. Pohl, Fluorescence detection of nitrogen dioxide with perylene/PMMA thin films, Sensors and Actuators B: Chemical 72, 51-55 (2001), doi: 10.1016/S0925-4005(00)00632-8

[10] N. Yamazoe, K. Shimanoe, Overview of gas sensor technology, in: D.K. Aswal, S.K. Gupta (Eds.), Science and Technology of Chemiresistor Gas Sensors, Nova Science Publishers Inc. New York, 2007, p. 8

[11] J. Brunet, V. Parra Garcia, A. Pauly, C. Varenne, B. Lauron, An optimised gas sensor microsystem for accurate and real-time measurement of nitrogen dioxide at ppb level, Sensors and Actuators B: Chemical 134, 632-639 (2008), doi: 10.1016/j.snb.2008.06.010

[12] J. Hennemann, T. Sauerwald, C-D. Kohl, T. Wagner, M. Bognitzki, A. Greiner, Electrospun copper oxide nanofibers for $\mathrm{H}_{2} \mathrm{~S}$ dosimetry, Phys. Status Solidi A 209, 911-916 (2012), doi: 10.1002/pssa.201100588

[13] D.J. Kubinski, J.H. Visser, Sensor and method for determining the ammonia loading of a zeolite SCR catalyst, Sensors and Actuators $B$ : Chemical 130, 425-429 (2008), doi: 10.1016/j.snb.2007.09.007

[14] A. Groß, S.R. Bishop, D.J. Yang, H.L. Tuller, R. Moos, The electrical properties of $\mathrm{NO}_{x}$-storing carbonates during $\mathrm{NO}_{\mathrm{x}}$ exposure, Solid State lonics 225, 317-323 (2012); doi: 10.1016/j.ssi.2012.05.009
[15] O.K. Varghese, P.D. Kichambre, D. Gong, K.G. Ong, E.C. Dickey, C.A. Grimes, Gas sensing characteristics of multi-wall carbon nanotubes, Sensors and Actuators B: Chemical 81, 32-41 (2001), doi: 10.1016/S0925-4005(01)00923-6

[16] J. Li, Y. Lu, Q. Ye, M. Cinke, J. Han, M. Meyyappan, Carbon nanotube sensors for gas and organic vapor detection, Nano Letters 3, 929933 (2003), doi: 10.1021/nl034220x

[17] A. Helwig, G. Müller, J.A. Garrido, M. Eickhoff, Gas sensing properties of hydrogen-terminated diamond, Sensors and Actuators B: Chemical 133, 156-165 (2008), doi: 10.1016/j.snb.2008.02.007

[18] G. Beulertz, A. Groß, R. Moos, D.J. Kubinski, J.H. Visser, Determining the total amount of $\mathrm{NO}_{x}$ in a gas stream - Advances in the accumulating gas sensor principle, Sensors and Actuators B: Chemical 175, 157-162 (2012), doi: 10.1016/j.snb.2012.02.017

[19] A. Helwig, G. Müller, G. Sberveglieri, M. Eickhoff, On the Low-Temperature Response of Semiconductor Gas Sensors, Journal of Sensors 2009, 1-18 (2009), doi: 10.1155/2009/620720

[20] A. Brandenburg, J. Kita, A. Groß, R. Moos, Novel tube-type LTCC transducers with buried heaters and inner interdigitated electrodes as a platform for gas sensing at various high temperatures, Sensors and Actuators B: Chemical, in press (2013), doi: 10.1016/j.snb.2012.12.119

[21] Directive 2008/50/EC of the European Parliament and of the Council of 21 May 2008 on Ambient Air Quality and Cleaner Air for Europe. Off. J. EU 2008, L152/1.

[22] A. Geupel, D.J. Kubinski, S. Mulla, T.H. Ballinger, $\mathrm{H}-\mathrm{Y}$. Chen, J.H. Visser, R. Moos, Integrating $\mathrm{NO}_{x}$ sensor for automotive exhausts-a novel concept, Sensor Letters 9, 311-315 (2011), doi: 10.1166/sl.2011.1471

[23] A. Groß, T. Weller; H.L. Tuller, R. Moos, Electrical conductivity study of $\mathrm{NO}_{x}$ trap materials $\mathrm{BaCO}_{3}$ and $\mathrm{K}_{2} \mathrm{CO}_{3} / \mathrm{La}-\mathrm{Al}_{2} \mathrm{O}_{3}$ during $\mathrm{NO}_{\mathrm{x}}$ exposure, Sensors and Actuators B: Chemical, accepted for publication (2013)

[24] A. Groß, D. Hanft, G. Beulertz, I. Marr, D.J. Kubinski, J.H. Visser, R. Moos, The effect of $\mathrm{SO}_{2}$ on the sensitive layer of a $\mathrm{NO}_{\mathrm{x}}$ dosimeter, Sensors and Actuators B: Chemical, in press (2012), doi: 10.1016/j.snb.2012.10.039

[25] A. Helwig, S. Beer, G. Müller, Breathing mode gas detection, Sensors and Actuators B: Chemical, in press (2012), doi: 10.1016/j.snb.2012.07.088. 